\title{
A linguagem visual transconfessional da xilogravura pietista "O caminho largo e o caminho estreito", de Charlotte Reihlen
}

\author{
The Transconfessional Visual Language of Pietist xylography \\ "The Broad and narrow Way" by Charlotte Reihlen
}

Helmut Renders*

\begin{abstract}
Resumo
A xilogravura "O caminho largo e o caminho estreito", de Charlotte Reihlen, criada em 1862, é considerada um dos ícones da cultura visual evangélica que se tornou um fenômeno mundial. $\mathrm{O}$ artigo apresenta sua linguagem religiosa como releitura de duas gravuras do artista da reforma católica Hieronymus Wierix (1553-1619), conhecidas pelo mesmo nome em holandês (De smalle en de brede Weg, 1600 e 1619) e sugere ainda influências da obra $A$ nova Jerusalém, originalmente da Suíça, com alta difusão na França e na Alemanha. Enquanto os comentários em relação à dependência de Wierix representam mais ajustes de pesquisas anteriores, avança o texto a respeito da influência da outra obra e no detalhamento de temas em comum nas obras de Wierix e da Suíça, mas, omitidos em Reihlen. Finalmente, transparece a gravura de Reihlen como uma obra pietista luterana que articula uma linguagem religiosa, ao mesmo tempo em proximidade como em distinção de linguagens pictóricas da contrarreforma e do mundo reformado.
\end{abstract}

Palavras-chave: Linguagem religiosa; Cultura visual religiosa; O caminho largo e o caminho estreito; Charlotte Reihlen; Hieronymus Wierix; François Georgin.

\begin{abstract}
A xilogravura "O caminho largo e o caminho estreito", de Charlotte Reihlen, criado em 1862, é The xylography "The Broad and narrow Way" by Charlotte Reihlen, created in 1862, is considered one of the icons of visual evangelical culture that has become a worldwide phenomenon. This article presents the religious language of xilography as a reprint of two engravings by the artist of the Catholic Reformation Hieronymus Wierix (1553-1619), known by the same name in Dutch (De smalle en de brede Weg, 1600 and 1619) and also suggests influences of the work "The new Jerusalem", originally from Switzerland, with high diffusion in France and Germany. While the commentaries on Wierix's dependence represent more adjustments of previous research, the text advances on the influence of the other work and on the detailing of common themes in the works of Wierix and Switzerland but omitted in Reihlen. Finally, Reihlen's xilography appears as a Lutheran pietist work that articulates a religious language at the same time in proximity as in distinction of pictorial languages from the counterreformation and the Reformed world.
\end{abstract}

Keywords: Religious language. Religious visual culture. The broad and the narrow way. Charlotte Reihlen; Hieronymus Wierix. François Georgin.

Artigo recebido em 04 de março de 2016 e aprovado em 08 de dezembro de 2016.

* Doutor em Ciências da Religião. Professor do Programa de Pós-Graduação em Ciências da Religião e da Faculdade de Teologia da Universidade Metodista de São Paulo - UMESP. País de origem: Alemanha. E-mail: helmut.renders@metodista.br 


\section{Introdução}

Em 2014, Leonildo Silveira Campos ${ }^{1}$ publicou um artigo (2014b) e um capítulo em livro (2014a) sobre um ícone da cultura visual religiosa protestante, a xilografia Os dois caminhos lançada em 1867 por Charlotte Reihlen (1805-1868)² e comentou:

\footnotetext{
${ }^{1}$ Uma versão anterior desse texto foi publicada em Horizonte por Leonildo Silveira Campos (2014b, p. 339-381).

2 Informações sobre C. Reihlen veja Martin Scharfe (1968, p. 149-150 e 267-270; 1967, p. 70-71; 1980, p. 84-87). Uma biografia científica de Reihlen não existe, mas uma de uma sociedade histórica: LANG, Friedrich G. Lang, 2014. Existe somente uma tese de doutorado que explora a visão da tecnologia pelo quadro de Carmen Czajkowski (2005).
} 
Figura 1: Charlotte Reihlen. Caminho largo e estreito. [1932] Edição brasileira

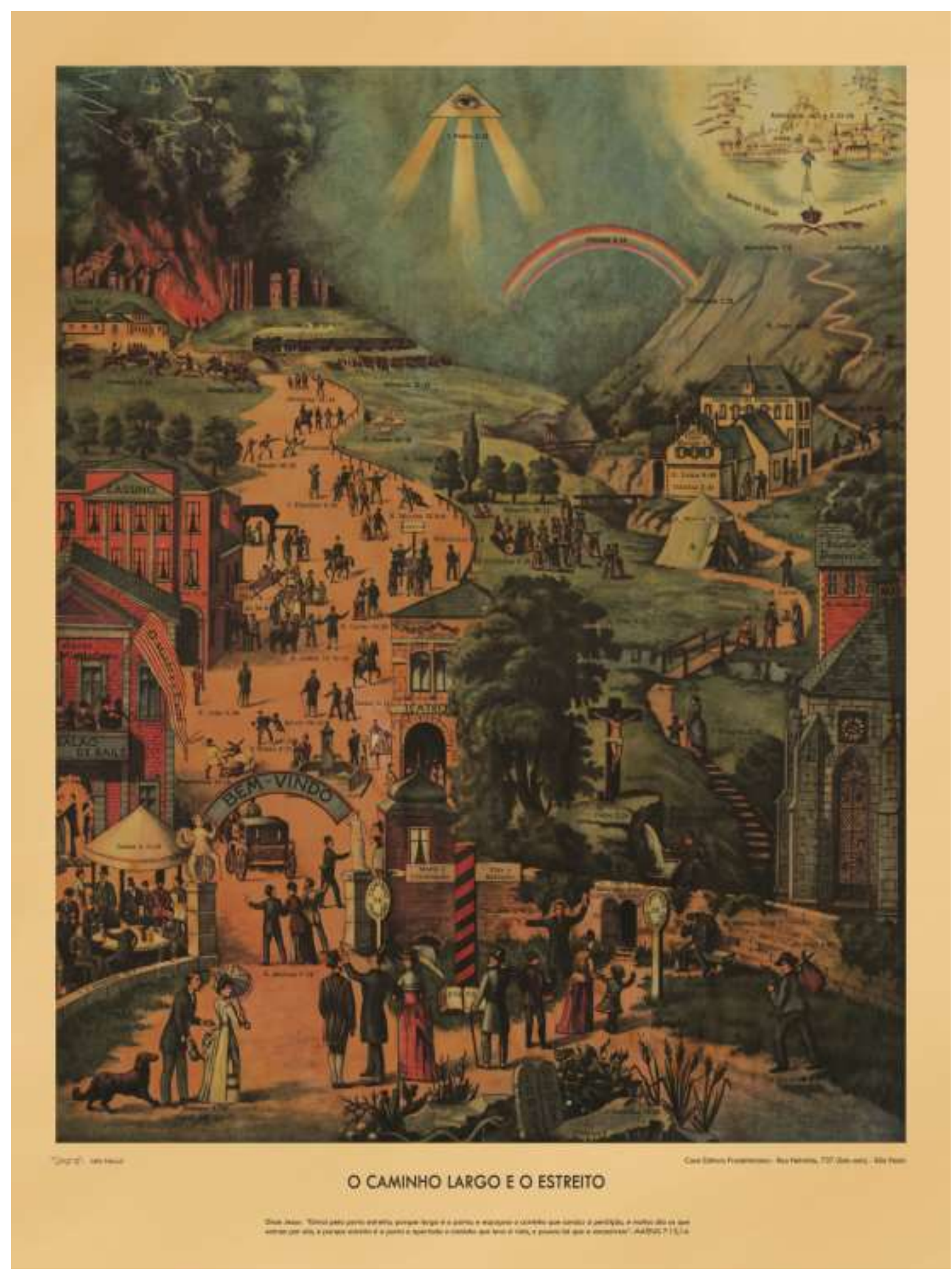

Fonte: Foto do autor, [original de 1932] 
No mesmo livro do capítulo de Campos, tínhamos explorado a importância dos irmãos Jan (1549-1625), Gerônimo [Hieronymus] (1553-1619) e Antônio [Antonius] (1555/59-1604) Wierix 3 para a construção da cultura visual colonial da América Latina. Neste texto, focamos a influência em outra obra, posteriormente divulgada pelas missões protestantes, inclusive no Brasil, O livrinho do coração, de Johannes Evangelista Gossner, livro de emblemas criado por um padre católico alemão que, mais tarde, se tornou luterano (RENDERS, 2012, p. 77-105). Era a primeira vez que vimos como, por meio da cultura visual supostamente protestante, foram absorvidos livros com emblemas católicos inteiros sem mudanças significativas.

Entretanto, somente depois da publicação desse livro de 2012 encontramos uma gravura criada por Hieronymus Wierix em 1619, posteriormente chamada $O$ caminho estreito e largo 4 , cuja proximidade visual com a xilografia de Charlotte Reihlen chamou imediatamente a nossa atenção (cf. também MASING, 1988, p. 258-267). Seguindo essa pista, encontramos logo na pesquisa uma afirmação:

Se perguntamos de onde Reihlen tirou a sua inspiração, somos levados ao passado da história espiritual. Por volta de 1600 , o gravador Hieronymus Wierix (1553-1619) criou uma gravura com base em um trabalho por Hendrik van Balen (1575-1632) (SHANTZ, 2005. p. 158).

Mesmo que nossa pesquisa apontasse uma obra de 1619, e não de 1600, o que explica facilmente por que Wierix tinha criado duas gravuras com o mesmo motivo, encontramos pela segunda vez um vínculo iconográfico entre gravuras católicas e protestantes.

Contudo, não paramos por aí. Além das obras de Wierix, encontramos durante nossa investigação outro conjunto de obras cujos elementos visuais nos pareciam também possíveis inspirações para a obra de Charlotte Reihlen. Trata-se

\footnotetext{
${ }^{3}$ Quanto à família, consulte Roelof van Straten (2010). Já a respeito da obra dos três gravadores, conferir Marie Mauquoy-Hendrick (1978-1983).

${ }^{4} \mathrm{Na}$ literatura, usa-se o nome em holandês: "De smalle en de brede Weg". Na gravura, o título aparece, entretanto, na legenda abaixo da gravura, em latim.
} 
de um grupo de xilografias parecidas que sempre retratam na parte superior a nova Jerusalém e na inferior um conjunto de três caminhos, dos quais um leva ao céu e dois ao inferno.5 Observamos, primeiro, as versões criadas pelo francês François Georgin, para depois aprendermos que o motivo original vinha provavelmente da Suíça, com posteriores edições. Primeiro, as já mencionadas edições francesas, logo seguidas por edições alemãs. Mais uma vez, tratava-se de um intercâmbio visual internacional e interconfessional.

Enquanto apresentaremos as duas gravuras de Wierix e uma de Georgin, em estudos detalhados (RENDERS, 2016a; 2016b), segundo o método sugerido por Ernst Panofsky (1986, p. 47-65; 1977), propomos neste artigo um estudo comparativo, focando os aspectos visuais e composicionais das obras de Reihlen, de Wierix e das gravuras Os Três Caminhos. Procuramos determinar possíveis dependências, como também esclarecer diferenças. Pretendemos mostrar que uma investigação na perspectiva da cultura visual de uma obra é capaz de mostrar novos aspectos relacionados à sua criação e ao seu significado. Em nosso caso, uma obra pietista alemã, eventualmente, dialoga muito mais com a cultura visual da reforma católica do que com a vertente reformada do protestantismo.

Com essa perspectiva dos estudos visuais, pretendemos, então, trazer um subsídio adicional aos estudos apresentados por Campos (2014a e 2014b), Marques Delcides (2013)6, Lyndon de Araújo Santos (2006a7; 2006b, p. 217-244 e 2004) e Douglas Teixeira Monteiro (1975, p. 21-29) ${ }^{8}$. Apesar de Santos (2006, p. 234 -235) mencionar explicitamente uma proximidade entre o pietismo alemão e o

\footnotetext{
${ }^{5}$ O que varia são os títulos - “O novo Jerusalém”, "Os três caminhos", "O caminho para a nova Jerusalém”, ou “O caminho para o céu e para o inferno" - e as pessoas retratadas.

${ }^{6}$ No seu estudo antropológico, Marques Delcides interpreta a composição dual do quadro à luz da antropologia simétrica de Bruno Latour (1994), como representação de uma antropologia dualista. Interessante para a perspectiva dos estudos da cultura visual é a sua reflexão sobre o aspecto da recepção que ele apresenta como uma interação entre um "olhar sinistro" de Deus e o olhar do/a leitor/a (DELCIDES, 2013, p. 55-57).

7 O autor apresenta o quadro (SANTOS, 2006a, p. 232-259) como paradigma histórico da face protestante do sagrado de "formas diferenciadas da vida religiosa social nos gestos, nas posturas, na linguagem e na ética" (SANTOS, 2006a, p. 17). Quanto à perspectiva dos estudos da cultura visual, Santos destaca também a recepção, com base em David Morgan (apud SANTOS, 2006, p. 236) e seu conceito da empatia. Santos reconhece a singularidade do uso da xilogravura de Reihlen e fala de "uma interessante exceção [...] [que] [...] traz instigantes questionamentos relativos aos pensamentos e às imagens cultivados pelo protestantismo durante décadas" (SANTOS, 2006, p. 238). Em nossa perspectiva, isso cria certa tensão com sua afirmação inicial da página 17.

${ }^{8} \mathrm{O}$ autor dedicou-se a uma divisão em sete áreas especiais - enquanto Marques Delcides (2013, pp. 62 - 69) favorece uma divisão em três blocos.
} 
catolicismo medieval quanto ao deslocamento "da vida religiosa para a interioridade do coração", os outros autores acima mencionados enxergam na obra de Reihlen uma visualização “do” protestantismo, "uma síntese da mensagem pietista e puritana do protestantismo de missão, portador de uma visão de mundo dualista, dogmática e exclusivista" (CAMPOS, 2014a); mais especificamente, o protestantismo missionário "fundamentalista": "A vida moral protestante é apresentada a partir de sua vertente missionária fundamentalista. Parte-se de um dualismo dessa moral presente na proposta estética puritano-pietista do livro $O$ peregrino, mas principalmente da iconografia 'Os dois caminhos'” (DELCIDES, 2013, p. 7).

O que nós acrescentaremos a estes estudos é uma visão ampliada do próprio ambiente pietista alemão quanto aos seus intercâmbios com ambientes católicos, o que eventualmente explica até a sua aceitação no contexto brasileiro, justamente não por ser diferente, mas por seguir um modelo visual conhecido dos católicos e recém-convertidos. Isso, aliás, jogaria eventualmente também uma luz adicional ao que Marques Delcides (2013, p. 70), Lyndon de Araújo Santos (2006b, p. 226) e Douglas Teixeira Monteiro (1975. p. 23) consideram como momento inicial da divulgação do quadro: "os primeiros exemplares do quadro que chegaram ao Brasil foram trazidos por Ricardo Mayorga, um ex-padre católico convertido ao protestantismo". Afinal, as ênfases do quadro de Reihlen são tipicamente protestantes ou típicas para uma vertente religiosa que se encontra tanto no catolicismo quanto entre os evangélicos?

No primeiro tópico, procuramos identificar possíveis fontes que poderiam ter servido como inspiração visual para a obra Os dois caminhos de Reihlen, e propomos duas fontes visuais principais; no segundo tópico, verificamos a possível relação entre as xilogravuras dos três caminhos e a xilogravura de Charlotte Reihlen, inclusive para mostrar como na época de Reihlen existia um intercâmbio transconfessional em nível da arte cristã popular; no terceiro tópico, evidenciamos os ecos visuais das duas gravuras de Hieronymus Wierix, de 1600 e 1619, com o 
tema dos dois caminhos na obra de Charlotte Reihlen. Finalmente, em um quarto tópico, unimos aqueles elementos comuns das gravuras dos três caminhos e dos dois caminhos de Hieronymus Wierix, que Charlotte Reihlen não citou. Aqui vamos alegar que essas omissões representam uma posição religiosa moderna, mesmo que seja bem moderada.9 Pretendemos, dessa forma, mostrar como um ícone da cultura visual pietista do século 19, com enorme reputação em círculos evangélicos ao longo do século 20 no Brasil, cita de fato amplamente obras católicas do século 17 e, em grau menor, uma obra do século 19, apreciada por protestantes e católicos.

\section{0 motivo dos dois caminhos em obras dos séculos 16 a 18 como possíveis fontes da obra de Reihlen}

Uma obra artística de uma pietista alemã, que se assume provavelmente de imediato, deve inspirar-se em obras protestantes e, dentre elas, preferencialmente, em obras luteranas. Entretanto, uma das primeiras surpresas é que o motivo dos dois caminhos, inicialmente, não foi explorado por artistas luteranos da época da Reforma. Assim, não temos nenhuma referência direta desse tipo em Albrecht Dürer (1471-1528), Lucas Cranach, o velho (1473-1553), ou Lucas Cranach, o jovem (1515-1586). O que se encontra são a alegoria Lei e graça ou Lei e evangelho ${ }^{10}$ ou $A$ escolha de Hércules ${ }^{11}$.

Já no protestantismo da tradição reformada, o motivo é recorrente desde o século 16, e isso tanto como metáfora literária quanto em gravuras e pinturas e, às vezes, em combinação. Assim sugere Santos (2006, p. 234), em dependência de Wharey (1960), que Reihlen teria seguido John Bunyan e, especialmente, as "ilustrações [do caminho largo e caminho estreito] encontradas nas edições de 1678, 1679 e 1682”, do livro O progresso do peregrino. Entretanto, vistas uma por uma, essas gravuras representam cenas isoladas do caminhar da "cidade de

\footnotetext{
${ }^{9}$ Evidentemente, uma das críticas frequentes à obra, sua visão dualista, já em si poderia ser lida como simples reflexo de uma lógica cartesiana, ergo, moderna.

${ }^{10}$ As obra são de Lucas Cranach, o velho: “Lei e graça” (1529), "Lei e graça - a justificação do pecador (1531) e “Lei e evangelho" (1551) [Para ter acesso a essas pinturas, ver a bibliografia].

${ }^{11}$ Albrecht Duerer .
} 
destruição" à “cidade celestial”, sem apresentar qualquer detalhe iconográfico específico encontrado na obra de Reihlen, além de não compor um conjunto, como é o caso da xilogravura de Reihlen.

A relação com Bunyan é, então, em primeiro lugar, de natureza metafórica e não visual. Além disso, seria provavelmente ainda mais adequado dizer que Bunyan literalizou o que, paralelamente, na sua época, já tinha sido visualizado em gravuras e livros com emblemas, por mais do que um século, ${ }^{12}$ tanto por artistas da reforma católica como por artistas do protestantismo reformado. Vejamos, em seguida, uma lista de gravuras com o tema dos dois caminhos dos séculos 16 a 18:

Tabela 1: Motivo dos dois caminhos nos Países Baixos

\begin{tabular}{|c|c|c|c|}
\hline Criação & Autor/es & Confissãa & Título \\
\hline 1570 & $\begin{array}{c}\text { Jan Collaert naar } \\
\text { Degenhardus } \\
(1525 / 30-1580)\end{array}$ & Católica & $\begin{array}{c}\text { Smenschens Salich[eid], } \\
\text { en v[er]doemenis } \\
\text { beteekenis }\end{array}$ \\
\hline 1571 & $\begin{array}{c}\text { Maarten van Heemskerck } \\
(1498-1574)\end{array}$ & Católica & De brede en de smalle weg \\
\hline 1579 & $\begin{array}{l}\text { Gerard de Jode } \\
(1509-1591)\end{array}$ & Católica & $\begin{array}{l}\text { Hercules elegit virtutis } \\
\text { calem (Hércules escola o } \\
\text { caminho da virtude) }\end{array}$ \\
\hline 1583 & $\begin{array}{c}\text { Johannes van Doetecum, o } \\
\text { velho (1554-1605) e } \\
\text { Lucas van Doetecum } \\
(?-1589)\end{array}$ & $\begin{array}{c}\text { Ambos } \\
\text { Reformados }\end{array}$ & De smalle en brede Weg \\
\hline 1584 & $\begin{array}{l}\text { Gilles Mostaert } \\
(1528-1598)\end{array}$ & Católica & $\begin{array}{c}\text { De brede en smalle weg } \\
\text { met Christus tijdens de } \\
\text { bergrede }\end{array}$ \\
\hline 1590 & $\begin{array}{l}\text { Jan Wierix } \\
{[1549-1620]}\end{array}$ & Católica & $\begin{array}{l}\text { Hércules na encruzilhada } \\
\text { dos dois caminhos }\end{array}$ \\
\hline 1590 & $\begin{array}{l}\text { Frans Hogenberg } \\
(1535-1590)\end{array}$ & Católica & $\begin{array}{l}\text { De brede en de smalle } \\
\text { weg: allegorie op de } \\
\text { menselijke levensloop }\end{array}$ \\
\hline 1600 & $\begin{array}{c}\text { Hieronymus Wierix } \\
{[1553-1619]}\end{array}$ & Católica & De brede en de smalle weg \\
\hline
\end{tabular}

${ }^{12}$ Claus Bernet e Ingeborg Schmidt (2016, p. 28) mencionam “Gilles Mostaert, Maarten van Heemskerck, Hieronymus Wierix, Ludovicus van Leuven, Theodoor Rombouts, Cornelis Huyberts, Cornelis van Noorde...". 


\begin{tabular}{|c|c|c|c|}
\hline Criação & Autor/es & Confissão & Título \\
\hline 1611 & $\begin{array}{l}\text { Theodoor Rombouts } \\
(1597-1637)\end{array}$ & Reformada & $\begin{array}{c}\text { De brede end e smalle } \\
\text { Weg }\end{array}$ \\
\hline 1616 & Hieronymus Wierix & Católica & $\begin{array}{c}\text { De brede en de smalle } \\
\text { weg }\end{array}$ \\
\hline $1623-1653$ & $\begin{array}{l}\text { Pieter Symonsz Potter } \\
(1597-1652)\end{array}$ & Reformada & $\begin{array}{l}\text { Hercules op de } \\
\text { tweesprong }\end{array}$ \\
\hline 1629 & $\begin{array}{l}\text { Ludovicus van Leuven } \\
(1600-1661)\end{array}$ & Católica & $\begin{array}{c}\text { Os três caminhos } \\
\text { [ilustração de livro] }\end{array}$ \\
\hline 1639 & $\begin{array}{c}\text { Laurence Neter } \\
(1600 / 04-1649 / 69)\end{array}$ & Reformada & De brede en de smalle weg \\
\hline 1645 & $\begin{array}{c}\text { Karel van Mander } \\
(1548-1606)\end{array}$ & Reformada & $\begin{array}{c}\text { Allegorie met brede en } \\
\text { smalle pad }\end{array}$ \\
\hline 1649 & $\begin{array}{c}\text { Jan Christiaensz Micker } \\
(1598-1664)\end{array}$ & Reformada & Brede en smalle weg \\
\hline 1699 & $\begin{array}{c}\text { Jan Claesz ten Hoorn } \\
(1621-1715) \\
\end{array}$ & Reformada & Gesigt van de Hel \\
\hline 1699 & $\begin{array}{l}\text { Jan Luyken } \\
(1649-1712)\end{array}$ & Menonita & $\begin{array}{l}\text { Jongeling moet kiezen } \\
\text { tussen de brede en de } \\
\text { smalle weg } \\
\end{array}$ \\
\hline 1704 & $\begin{array}{c}\text { Cornelis Huyberts } \\
(1669-1712)\end{array}$ & Reformada & De smalle en brede Weg \\
\hline 1706-1707 & $\begin{array}{l}\text { Carel Allard } \\
(1648-1709) \\
\end{array}$ & Reformada & $\begin{array}{l}\text { Roma Pertubata / 't } \\
\text { Lusthofvan Momus }\end{array}$ \\
\hline 1712 & $\begin{array}{l}\text { Jan Luyken } \\
(1649-1712)\end{array}$ & Reformada & $\begin{array}{c}\text { Een engel wijst een } \\
\text { wandelaar op een smalle } \\
\text { weg die leidt naar het } \\
\text { hemels Sion }\end{array}$ \\
\hline 1712 & $\begin{array}{c}\text { Jan Luyken } \\
(1649-1712) \\
\end{array}$ & Reformada & $\begin{array}{c}\text { De smalle weg en de brede } \\
\text { weg }\end{array}$ \\
\hline 1767 & $\begin{array}{c}\text { Cornelis van Noorde } \\
(1731-1795)\end{array}$ & Reformada & De smalle en brede Weg \\
\hline
\end{tabular}

Fonte: Dados da pesquisa ${ }^{13}$

Sem nenhuma pretensão de apresentar uma relação completa, a Tabela 1 mostra a alta popularidade do tema nos Países Baixos. Também se percebe uma mudança de preferência em termos confessionais: entre 1570 e 1629 artistas comprometidos com a reforma católica são mais frequentes. A partir de 1639, dominam gravuras de artistas reformados.

\footnotetext{
${ }^{13}$ Basicamente, unimos aqui dados de nossas pesquisas em bancos de dados holandeses, ingleses, alemães, espanhóis e franceses e do livro de Claus Bernet e Ingeborg Schmidt (2016).
} 
Quem compara todas essas gravuras vai encontrar uma ou outra proximidade entre elas, porém, não uma padronização da linguagem visual, nem entre os artistas católicos, nem entre os artistas protestantes. Para nossa pesquisa, é importante que, entre estes artistas dos Países Baixos, em sua maioria os oriundos do Amsterdã protestante ou da Antuérpia católica, somente um artista parece ter influenciado a obra de Charlotte Reihlen diretamente: o católico Hieronymus Wierix. As razões para essa conclusão, mostraremos no terceiro tópico.

Relacionado com o motivo dos dois caminhos, na base de Mateus 7, aparecem na Renascença mais dois: o Épsilon de Pitágoras que, às vezes, é combinado com a versão cristã, ${ }^{14}$ e a Escolha de Hércules, o último em nossa lista, representada pelas obras de Gerard de Jode (1509-1591) e Pieter Symonsz Potter (1597-1652). É importante lembrar que os dois motivos da Antiguidade não enfatizam uma cosmologia "dualista", mas, uma antropologia que se concentra na virtude humana e que favorece um sujeito disposto a conduzir seu caminho (MESSIMERI, 2001, p. 145). A pergunta - se essa interpretação ou ênfase ainda se mantém para o século 19 -, pode ser levantada. Contudo, para as obras renascentistas do século 16, com ecos para o século 17 e 18, acreditamos que seja bastante relevante. ${ }^{15}$

\footnotetext{
${ }^{14}$ Assim, no caso das duas obras de Wierix de 1600 e 1619. Na literatura, o Épsilon de Pitágoras aparece na Nave dos loucos de Sebastian Brant (1494), que inspirou a pintura do mesmo nome de Hieronymus Bosch (1494). Em geral, porém, esse motivo se encontra mais em emblemas depois de 1534 .

${ }^{15}$ A questão do "moralismo" protestante, levantada na base da obra de Reihlen, em distinção de uma concepção moderna do mundo, deve ainda lidar com duas outras perguntas que, por sua vez, apontam para duas direções distintas. Primeiro, a ideia carrega em sim um surpreendente reducionismo: o protestantismo da missão dos séculos 19 e 20 não era uniforme. Os presbiterianos e metodistas, por exemplo, promoveram Reihlen, mas também o evangelho social. Segundo, diversos elementos considerados constitutivos para a moral puritana austera são quase idênticos aos hábitos promovidos pela escola filosófica da Estoa, cujo redescobrimento ocorre na época da Renascença. É muito provável - e os estudos do motivo na perspectiva da cultura visual mostram isso - que esses aspectos se encontram também num certo tipo de catolicismo, especialmente, da Reforma católica ou de uma parte dela. Seguindo essa lógica, dever-se-ia esperar um elemento transconfessional e não confessional.
} 


\section{0 motivo dos três caminhos em obras do século 19 como possíveis fontes da obra de Reihlen}

Enquanto no primeiro tópico evidenciou-se a época da Reforma até o século 18, identificamos nesse tópico uma obra extremamente popular na época da criação da obra de Reihlen. Trata-se de um grupo de xilografias com nomes variados - "A nova Jerusalém" (figura 2), "Os três caminhos da eternidade" (figura 3) e "O caminho para o céu e o caminho para a eternidade" - mas com uma composição padrão: a apresentação da nova Jerusalém e do inferno ou da boca do inferno e dos três caminhos.

Segundo David M. Hopkin (2003, p. 276), a primeira versão da gravura veio da Alemanha. Já Claus Bernet e Ingeborg Schmidt (2016, posição 405) identificaram um desenho suíço de 1800 como sua matriz, com uma primeira gravura criada em Zäsiwil, perto de Basileia em 1811, seguida por versões dos suíços Christian Kräyenbühl de Laenzlingen e Johannes Haas de Zug. Basileia era uma cidade reformada de um cantão reformado, mas Zug era uma cidade católica em um cantão católico.

$\mathrm{Na}$ Alemanha, a gravura aparece mais em territórios protestantes: Nuremberg (1837, por Renner), Stuttgart (1850, por Johann Heinrich Reinz) e Reutlingen (186o, por Ensslin \& Leiblin). Outrossim, ela se apresenta, igualmente, em uma edição alemã lançada por Jean Frédérick Wentzel, em Weissenburg, (Bavaria, Alemanha) (figura 2), que reproduzimos em seguida: 


\section{Figura 2: S.N. Wentzel, Jean Frédérick. A nova Jerusalém. Weissenburg, 1860}

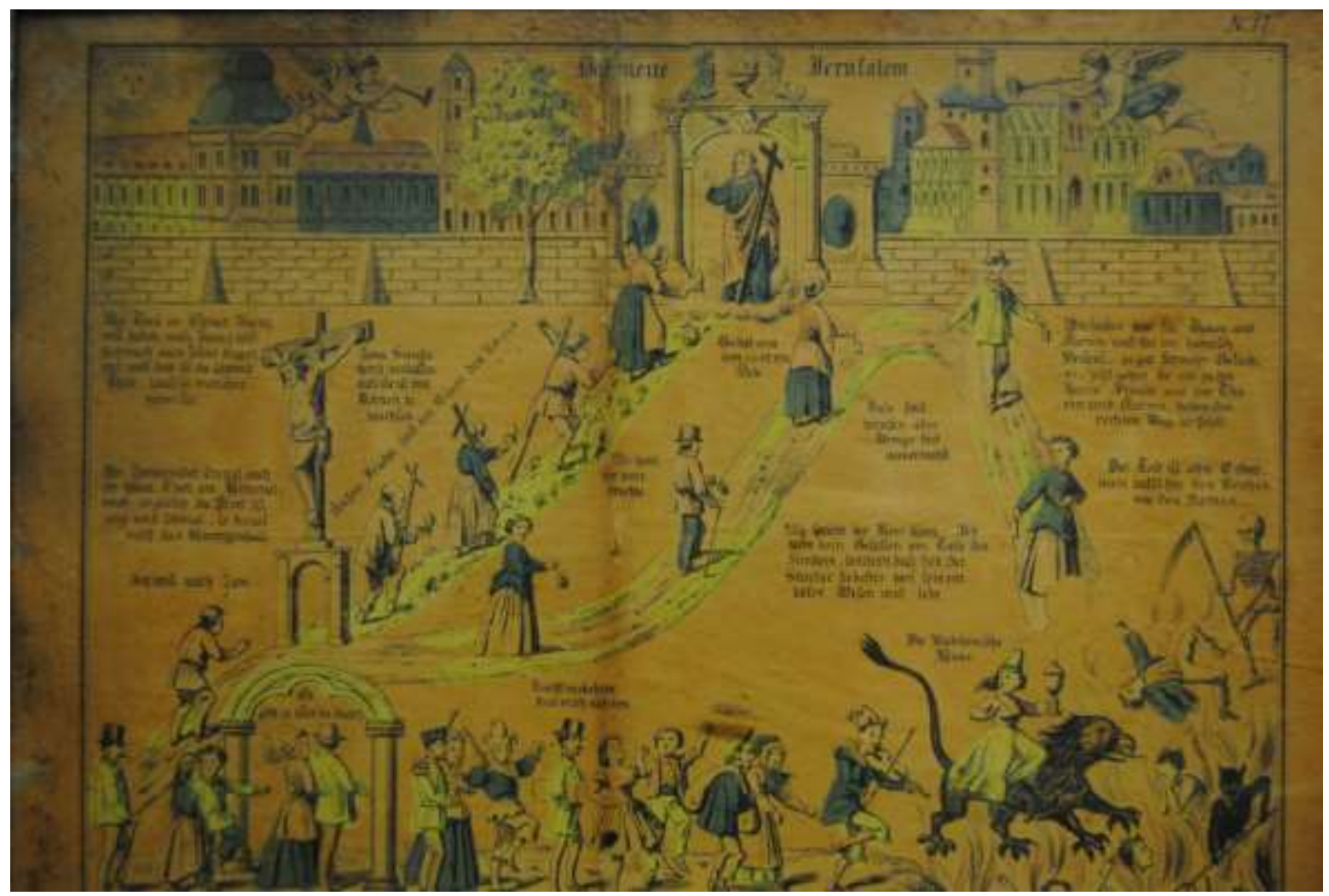

Fonte: Ebay, 1860

Antes das versões em língua alemã surgiram versões francesas. Entre 1800 e 1825, aparece a gravura A nova Jerusalém; entre 1825 e 1850, Os três caminhos da eternidade (figura 3); e, ao redor de 1837, uma edição bilíngue germano-francesa, com o título $O$ caminho para o céu e o caminho para a eternidade. ${ }^{16}$ Duas reedições são da mesma forma registradas: Leo S. Olski (1935, p. 409) menciona uma edição dos Três caminhos para a eternidade (figura 3), entre 1850 e 1860, e Sigrid Metken (1972, p. 32) identifica uma edição em língua alemã, publicada por volta de 1914, por Deckherr e Montbéliard. ${ }^{17}$ Além dessas edições europeias, existe

\footnotetext{
${ }^{16}$ Na página francesa não encontramos os anos de lançamentos mais exatos. Acrescemos essas informações de David M. Hopkins (2003, p. ix).

${ }_{17}$ Isabelle Saint-Martin (2009, p. 85-98) menciona que estas imagens populares serviram para outra série de cartazes dedicados ao tema $A$ santificação do domingo em que o caminho largo leva a uma fábrica e o caminho estreito, a uma igreja.
} 
uma edição estadunidense, em língua alemã. ${ }^{18}$ Quanto à confessionalidade, as edições franceses são, em sua maioria, católicas; a versão estadunidense é menonita. Reproduzimos a edição de 1825 :

Figura 3: François Georgin. Os três caminhos para a eternidade [1825]

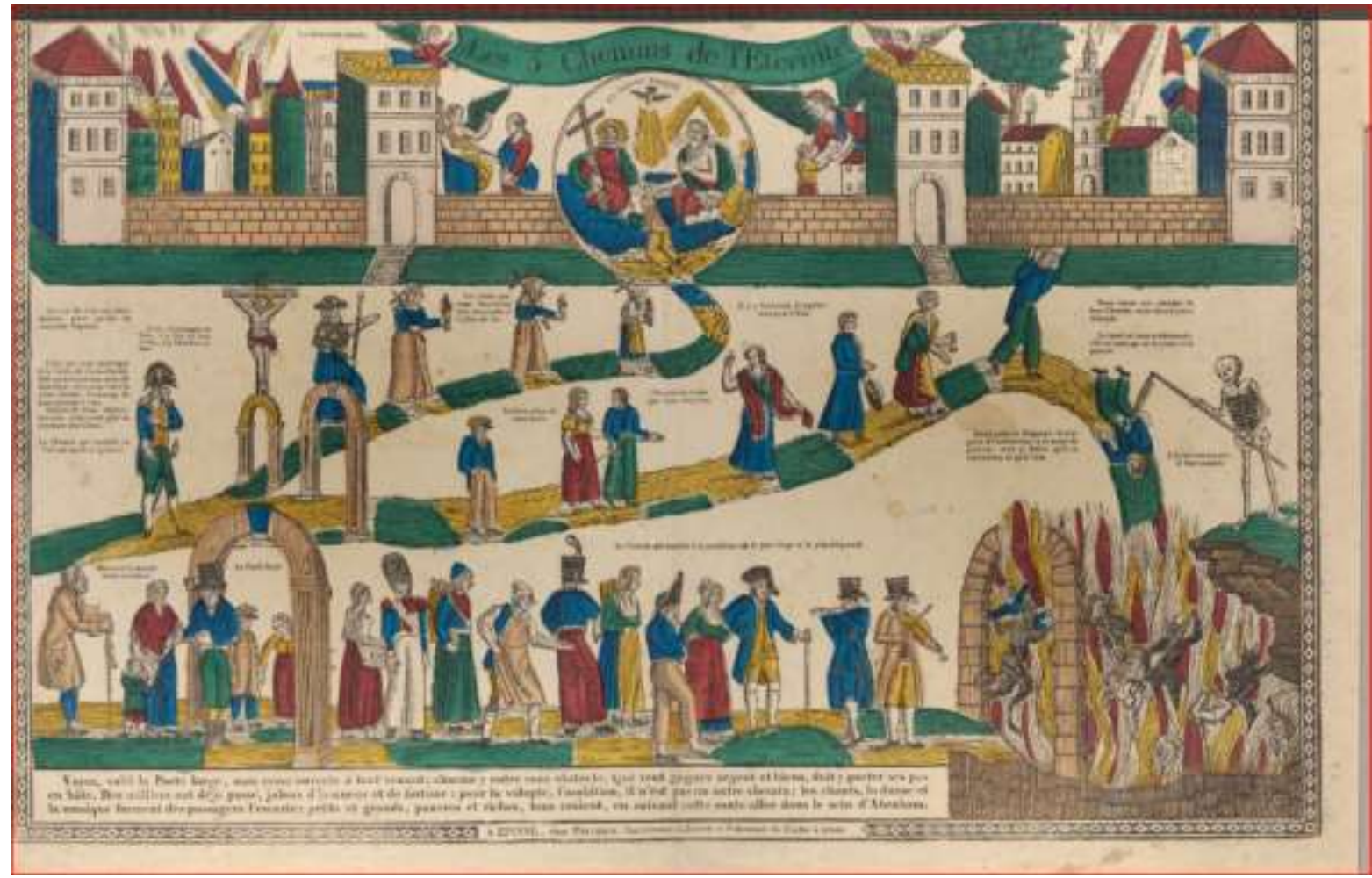

Fonte: Ministère de la Culture et de la Communication, France, 2016

Qual é a importância desse conjunto de xilogravuras para a nossa pesquisa? Primeiro, vendo as edições suíças, francesas, franco-alemãs e estadunidenses juntas, identifica-se um dinâmico intercâmbio que não somente transcende fronteiras nacionais, mas, também confessionais. Por exemplo: as duas gravuras acima apresentadas, apesar de serem do mesmo país, pertencem tanto a um meio

\footnotetext{
${ }^{18} \mathrm{O}$ título era Os caminhos distintos para a vida eterna ou para a maldição sem fim. Ele foi publicado em 1840, em Harrisburg, pelo menonita Gustav G. Peters (1793-1847). Peters aprendeu a arte de impressão ainda na Alemanha e se mudou para os Estados Unidos por volta de 1820. Como ele também publicou outra obra do publicitário francês Pellerin, entre elas, "O ciclo da vida", ele pode ter trazido o motivo da Alemanha ou da França. Peters também lançou uma versão estadunidense da obra $O$ coração do ser humano de Johannes Evangelista Gossner, obra muito conhecida em Stuttgart e posteriormente reeditada justamente junto à xilografia de Reihlen. Além da versão de Peters, houve outras de Herman William Ville (1789-1842) e J. G. Struphar (PIESKE, 1989, p. 13-22). O mesmo grupo editou também Johannes Evangelista Gossner (1832) e John Bunyan (1832).
} 
protestante (figura 2) (BERNET; SCHMIDT, 2016, posição 486) como a um meio católico (figura 3). Considerando todas as versões, esse intercâmbio internacional e interconfessional ocorreu no triângulo entre o norte da Suíça, o sudeste da França e o sudoeste da Alemanha. O centro desse intercâmbio era certamente a cidade de Basileia, mas Stuttgart, a cidade de Reihlen, ainda fazia parte dessa região.

Isso nos faz acreditar, primeiro, que Charlotte Reihlen cria sua obra em um ambiente religioso que, mediante a cultura material e visual religiosa popular, os intercâmbios interconfessionais eram não somente possíveis, mas, de fato, comuns. Em segundo lugar, é altamente provável que Reihlen conhecia essa obra em suas edições alemãs ou franco-alemãs. Apesar de ela não ter optado por este modelo, é plenamente possível que, mesmo assim, certos elementos dessa obra ainda entraram em sua gravura. Como critério da sua identificação procuramos aqueles elementos que não têm correspondentes com as gravuras de Hieronymus Wierix, identificadas por nós como segunda fonte de inspiração.

\section{Quadro 1 - Elementos do quadro "Nova Jerusalém” na obra de Reihlen}

\begin{tabular}{|c|c|c|c|}
\hline $\begin{array}{c}\text { Composição e } \\
\text { elementos }\end{array}$ & $\begin{array}{c}\text { F. Georgin, Os } \\
\text { três aminhos, } \\
\mathbf{1 8 2 5}\end{array}$ & $\begin{array}{c}\text { F. C. Wentzel, O } \\
\text { novo Jerusalém, } \\
\text { [186o] }\end{array}$ & $\begin{array}{c}\text { C. Reihlen, Der } \\
\text { breite und der } \\
\text { schmale Weg, } \\
\mathbf{1 8 6 7}\end{array}$ \\
\hline $\begin{array}{c}\text { A substituição do } \\
\text { ípsilon de } \\
\text { Pitágoras }\end{array}$ & Caminhos comuns & Caminhos comuns & Caminhos comuns \\
\hline $\begin{array}{c}\text { A representação } \\
\text { de portas ou } \\
\text { portais no início } \\
\text { de cada ca-minho }\end{array}$ & $\begin{array}{c}\text { Três portais sem } \\
\text { muros no início do } \\
\text { caminho largo e } \\
\text { estreito; dois ou três } \\
\text { portais no muro da } \\
\text { Nova Jerusalém. }\end{array}$ & $\begin{array}{c}\text { Três portais sem } \\
\text { muros no início de } \\
\text { cada caminho; uma } \\
\text { porta no muro da Nova } \\
\text { Jerusalém. }\end{array}$ & $\begin{array}{c}\text { Duas portas, } \\
\text { integradas em um } \\
\text { muro, no início do } \\
\text { caminho largo e do } \\
\text { caminho estreito. }\end{array}$ \\
\hline $\begin{array}{c}\text { A localização das } \\
\text { legendas }\end{array}$ & $\begin{array}{c}\text { Frases explicativas e } \\
\text { referências bíblicas } \\
\text { na gravura }\end{array}$ & $\begin{array}{c}\text { Frases explicativas e } \\
\text { referências bíblicas na } \\
\text { gravura }\end{array}$ & $\begin{array}{c}\text { Referências bíblicas na } \\
\text { gravura }\end{array}$ \\
\hline A coloração & $\begin{array}{c}\text { A xilogravura sempre } \\
\text { era colorida }\end{array}$ & $\begin{array}{c}\text { A xilogravura sempre } \\
\text { era colorida }\end{array}$ & $\begin{array}{c}\text { A gravura recebeu } \\
\text { cores na segunda } \\
\text { edição }\end{array}$ \\
\hline $\begin{array}{c}\text { O foco em pessoas } \\
\text { leigas do } \\
\text { ambiente urbano }\end{array}$ & $\begin{array}{c}\text { Leigos, mas também } \\
\text { um número } \\
\text { significativo de } \\
\text { soldados e religiosos }\end{array}$ & $\begin{array}{c}\text { Predominantemente } \\
\text { leigos. }\end{array}$ & Somente leigos \\
\hline
\end{tabular}

Fonte: Quadro elaborado pelo autor 
Neste tópico argumentamos que a obra de Reihlen surgiu em uma época e numa região que permitiam intercâmbios religiosos e que eles ocorriam, especialmente, através do uso de uma linguagem visual compartilhada. $\mathrm{O}$ uso do mesmo motivo pela “outra” confissão, aparentemente, não impediu nenhum dos lados de usá-lo também. Isso certamente favorecia a integração de alguns dos seus elementos, aprovados, digamos, tanto nos discursos católicos como nos discursos protestantes, reformados e luteranos, no processo da criação da obra nova de Reihlen.

\section{As gravuras $O$ caminho largo e estreito de Hieronymus Wierix do século 16 e 17 como possíveis fontes da obra de Reihlen}

A relação entre a obra de Reihlen e as obras de Wierix radicaliza tudo até agora afirmado. A obra de Wierix era um produto da Reforma católica, encomendada como discurso da contrarreforma, no sentido original da palavra: contra a reforma protestante. Mesmo assim, acreditamos que as gravuras de Wierix exerceram uma influência ainda mais clara na xilogravura de Reihlen do que as obras com o motivo dos três caminhos.

Essa influência passou por duas etapas: uma primeira mais indireta ou mediada; e uma segunda, direta. A influência indireta vinha das gravuras Uma vida farta - engano doloroso das pessoas mundanas de hoje ${ }^{19}$, de Kis, criada ao redor de 1800, em Cannstatt; e Espelho da alma ou a corrido da vida cotidiana ${ }^{20}$, criado por Johann Evangelist Ling; em 1840. ${ }^{21}$ Segundo a bibliografia alemã, ambas precursoras da xilogravura de Reihlen (LANG, 2014). Infelizmente, a

\footnotetext{
${ }^{19}$ Original: "Schmerzlicher Irrtum des üppigen Lebens jetziger Weltmenschen".

${ }^{20}$ Original: "Seelenspiegel oder der Wettlauf des alltäglichen Lebens".

${ }^{21}$ Há uma tradição alternativa que menciona como inspiração uma litografia com o título "O Caminho e o alvo do cristão" (Des Christen Weg und Ziel), produzida pela editora Damel de Stuttgart, no início do século 19 (assim VON HAUF, 2006, p. 198). Dificilmente trata-se da obra de Kis: Canstatt fica perto de Stuttgart, mas, certamente não teria sido confundida com Stuttgart, e o título da obra de Kis é claramente outro. Von Hauf se refere a Martin Scharfe (1990, p. 123-144) em um texto ao qual nós não tínhamos acesso.
} 
literatura brasileira se restringe à obra de 1840 , sem mencionar o nome do seu ator $^{22} \mathrm{e}$ sem analisar os aspectos visuais.

Dessa forma, perdem-se algumas informações interessantes. Primeiro, Kis é protestante e Ling é católico. Segundo, o protestante Kis revela uma dependência direta da gravura de 1619, do católico Wierix: ele não somente mantém seu plano de composição, mas também dois motivos característicos dessa obra, os grupos de soldados, na parte inferior e frontal da imagem, e o motivo da boca do inferno, destino final daqueles que andam no caminho largo. ${ }^{23}$ Já na obra do católico Ling, de 1840, a boca do inferno é reduzida a um conjunto de chamas e os soldados são substituídos por cidadãos e cidadãs comuns. Em Reihlen, as chamas se fundem com a cena de guerra, embora os grupos de pessoas leigas sejam mantidos.

Todavia, parece que Reihlen não somente seguiu Ling e Kis, via Ling, mas também integrou elementos das gravuras de Wierix na sua obra final, que em Kis e Link não aparecem. Primeiro, Kis e Ling desenham, atrás do portal (Kis) ou atrás dos dois portais junto a um muro (Ling), um cenário rural, enquanto Reihlen preenche essa parte da sua xilogravura com instituições urbanas. Esse detalhe é observado também por Marques Delcides (2013, p. 60): "No caminho largo há sinais de uma intensa vida urbana, com seus conflitos, assaltos violência". Chamamos isso de segunda influência de Wierix na obra de Reihlen; porém, agora, de forma mais direta: nos seus projetos gráficos predominam também aspectos urbanos. O segundo elemento, que chama a nossa atenção, é a representação tanto do olho divino com da nova Jerusalém na obra de Reihlen. Essa combinação não existe em Ling nem em Kis - eles desenham ou o céu ou a nova Jerusalém. A combinação existe somente na obra de 1600 de Wierix, porém, em uma subordinação (A Nova Jerusalém - na terra! - encontra-se abaixo da representação figurativa de Deus Pai). Quando combinamos as duas obras de Wierix e trocamos a

\footnotetext{
22 Quando Lyndon de Araújo Santos (2014, p. 217) fala da criação da obra "ao redor de 1843 na Alemanha" trata-se, na verdade, da litografia do católico Johann Evangelist Ling.

${ }^{23}$ Há mais um elemento na obra do protestante Kis que revela seu acesso a obras católicas. Em lugar da nova Jerusalém, ele retrata um meio círculo duplo de cabeças de anjos que, dessa forma, somente encontramos na gravura Os três caminhos, do católico Ludovicus van Leuven (1600-1661), de 1629.
} 
representação do Deus Pai pelo olho divino, chegamos exatamente à versão de Reihlen.

\section{Figura 6: Hieronymus Wierix. Caminho largo e o caminho estreito, 1600.}

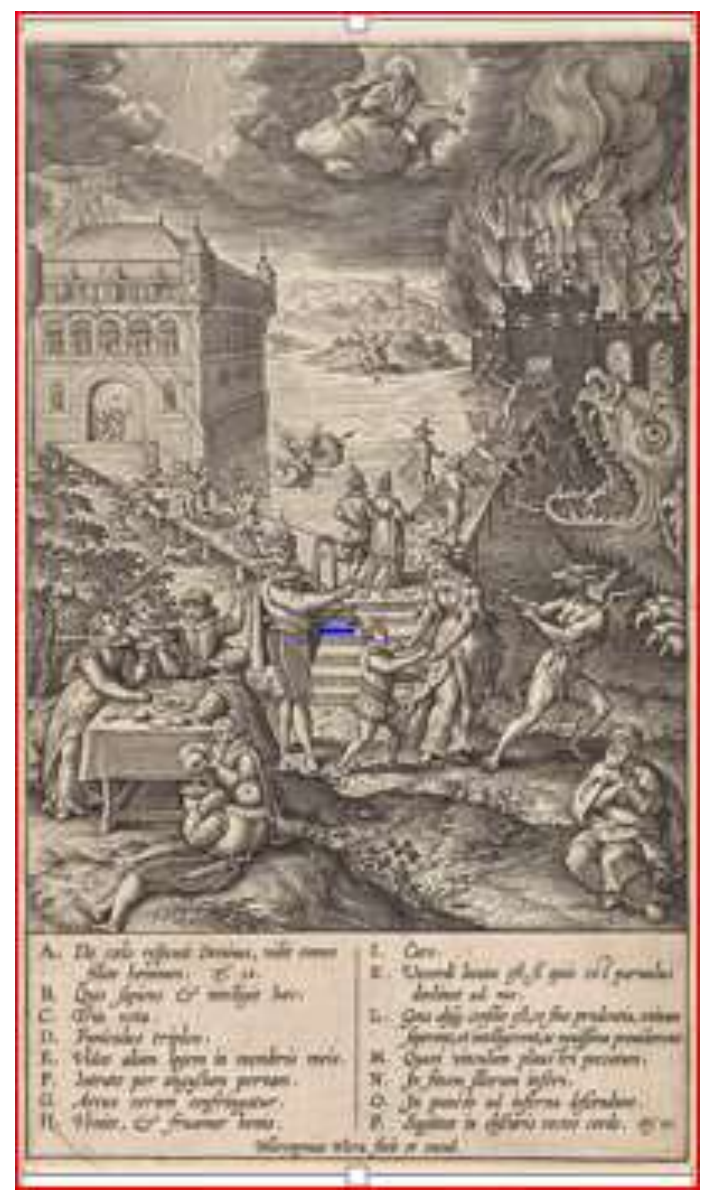

Fonte: Rijksmuseum, Holanda, 2016.

\section{Figura 7: Hieronymus Wierix. Caminho largo e o caminho estreito, 1619.}

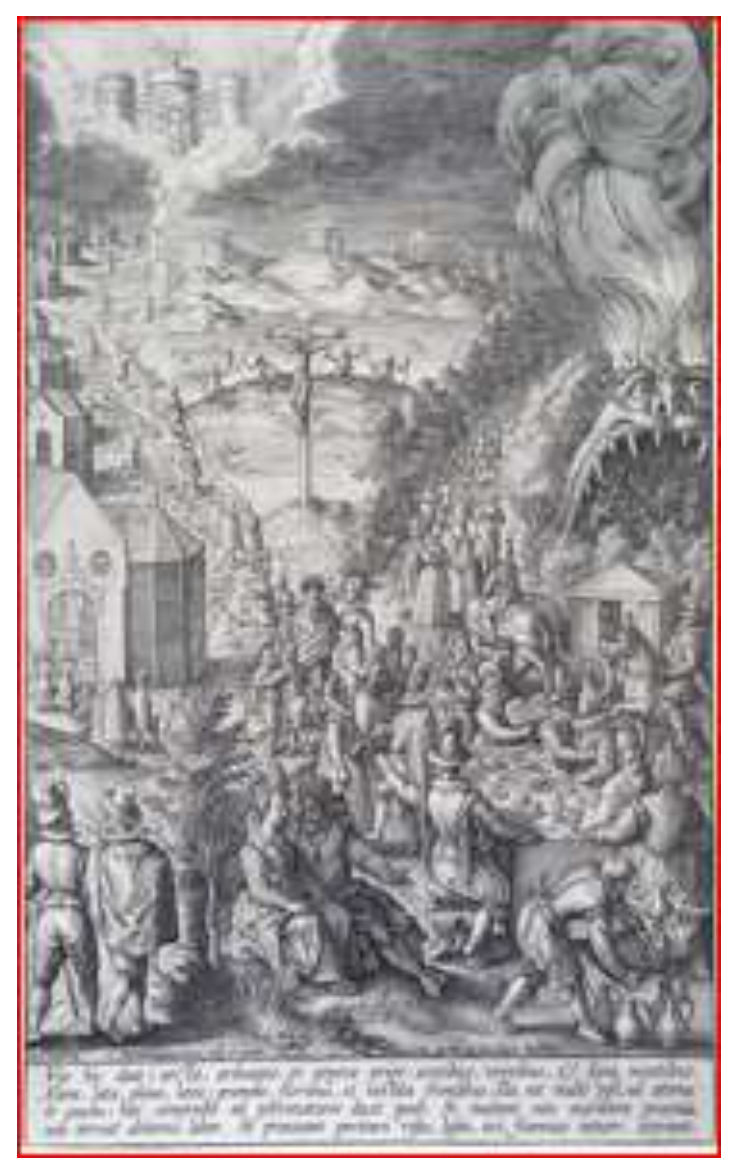

Fonte: Geheugenvannederland, Holanda, 2016.

Resumimos, no Quadro 2, os elementos que a obra de Reihlen parece ter em comum com as obras de Wierix: 


\section{Quadro 2 - Comparativo entre Wierix e Reihlen}

\begin{tabular}{|c|c|c|c|}
\hline $\begin{array}{l}\text { Composição e } \\
\text { elementos }\end{array}$ & $\begin{array}{l}\text { H. Wierix, De } \\
\text { brede en de } \\
\text { smale Weg, } \\
\text { [1600?] }\end{array}$ & $\begin{array}{c}\text { C. Reihlen, Der } \\
\text { breite und der } \\
\text { schmale Weg, } 1863\end{array}$ & $\begin{array}{c}\text { H. Wierix, De } \\
\text { brede en de } \\
\text { smale Weg, } \\
\text { [1619?] }\end{array}$ \\
\hline Acima, centro & Pai & Olho divino 24 & \\
\hline $\begin{array}{l}\text { Acima, direita } \\
\text { e esquerda }\end{array}$ & & $\begin{array}{l}\text { A Nova Jerusalém } \\
\text { nas nuvens }\end{array}$ & $\begin{array}{c}\text { A Nova } \\
\text { Jerusalém nas } \\
\text { nuvens }\end{array}$ \\
\hline Centro & $\begin{array}{l}\text { Os dois } \\
\text { caminhos }\end{array}$ & Pregação ao ar livre & $\begin{array}{l}\text { Os dois } \\
\text { caminhos }\end{array}$ \\
\hline $\begin{array}{l}\text { O Caminho } \\
\text { Estreito }\end{array}$ & & $\begin{array}{c}\text { Instituições } \\
\text { evangélicas [Igreja, } \\
\text { tenda, pregação ao } \\
\text { ar livre, centro de } \\
\text { diaconisas] }\end{array}$ & $\begin{array}{c}\text { Instituições } \\
\text { católicas } \\
\text { [Igreja e capela] }\end{array}$ \\
\hline Anjos & $\begin{array}{c}\text { Em diversas } \\
\text { portas }\end{array}$ & $\begin{array}{l}\text { Na porta da Nova } \\
\text { Jerusalém }\end{array}$ & $\begin{array}{c}\text { Na porta da } \\
\text { igreja, na porta } \\
\text { da Nova } \\
\text { Jerusalém }\end{array}$ \\
\hline Portões & $\begin{array}{l}\text { Do caminho } \\
\text { largo }\end{array}$ & Dos dois caminhos & Nenhum portão \\
\hline
\end{tabular}

Fonte: Tabela elaborada pelo autor

Em seguida (figura 8) marcamos os elementos-chave na xilografia de Charlotte Reihlen, que correspondem somente à gravura de De brede en de smalle Weg, de Hieronymus Wierix, de 1600 (triângulos); na gravura de De brede en de smalle Weg, de Hieronymus Wierix, de 1619 (rhombus), e nas duas gravuras de De brede en de smalle Weg, de Hieronymus Wierix, de 1600 e 1619 (círculos).

\footnotetext{
${ }^{24}$ Nas obras de Ling (1840) e Kis (1800) aparece somente a nova Jerusalém.
} 
Figura 8: Reihlen e Georgin: convergências temáticas e formais

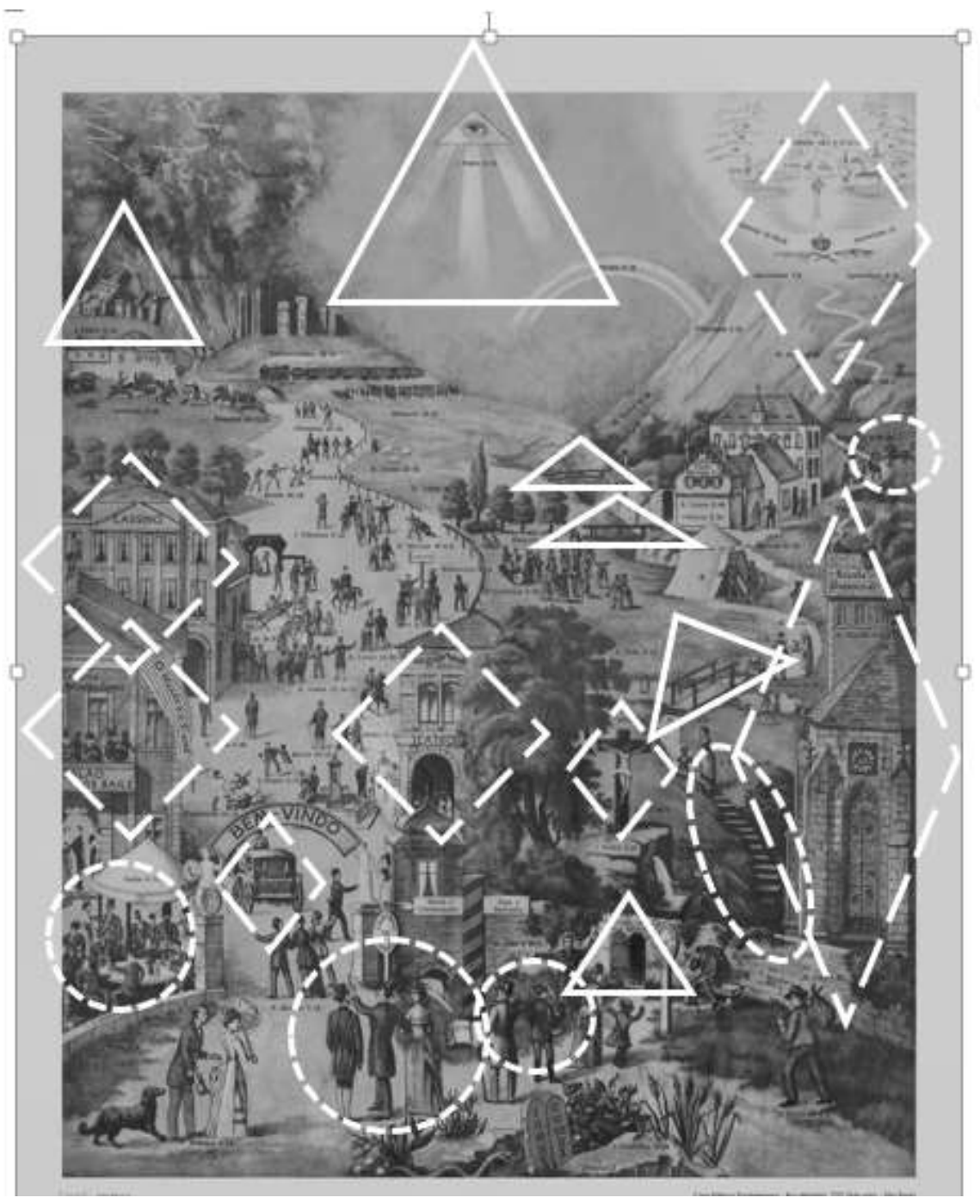

Fonte: Foto adaptada do autor, [original de 1932]

O número de elementos correspondentes é significativo, mas, certamente, o aspecto mais chamativo é a dependência direta da composição usada por Reihlen (figura 10) da obra de Wierix (figura 9), de 1619, mostradas a seguir: 
Figura 9: Hieronymus Wierix. Os dois caminhos, 1619

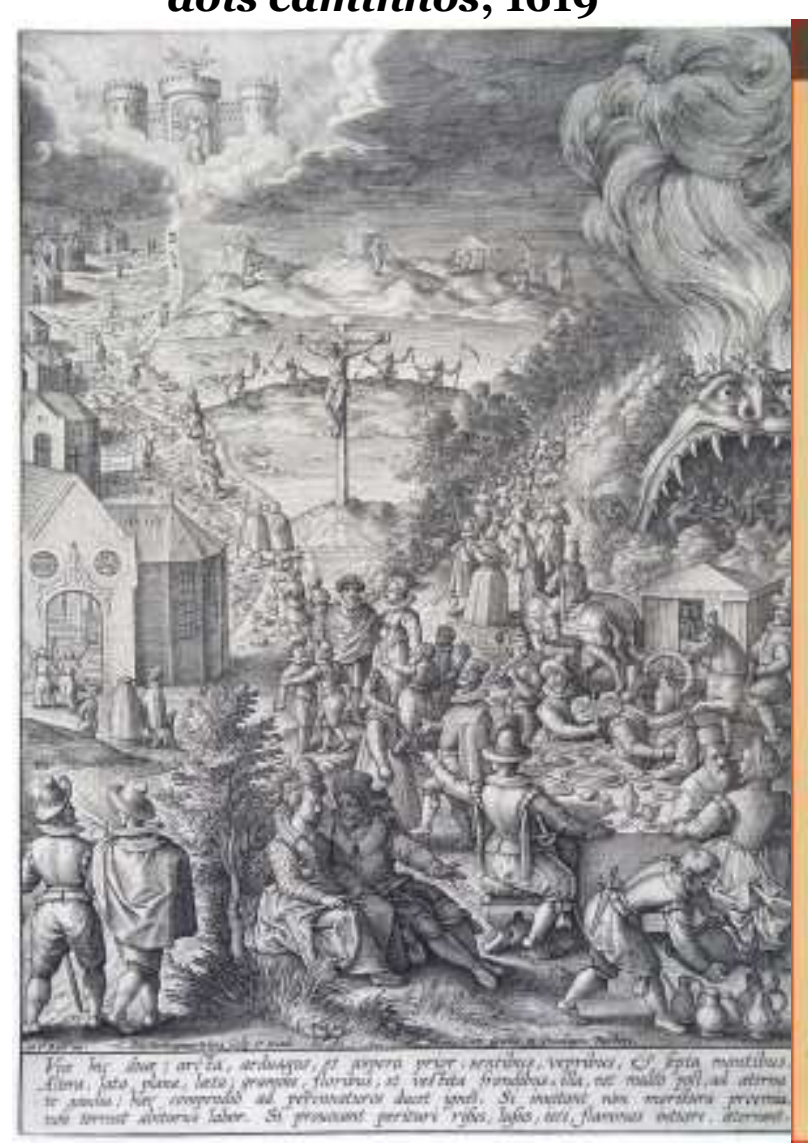

Fonte: Rijksmuseum, Holanda, 2016.
Figura 10: Charlotte Reihlen. Os dois caminhos, 1862.

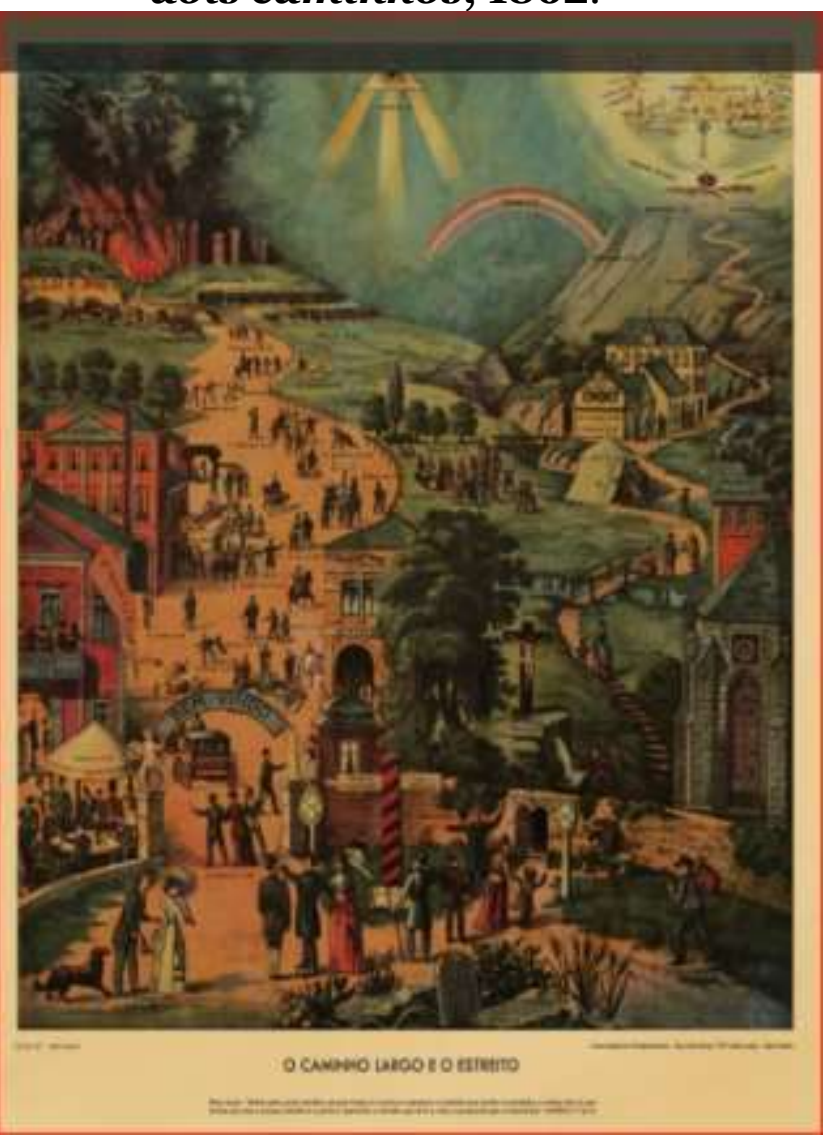

Fonte: Foto do autor, [original de 1932]

Estudando o aspecto composicional, chama a atenção a inversão dos lados. No caso de Wierix, podemos supor, como base, uma perspectiva teocêntrica. Na gravura de 1600, Cristo olha dos céus na direção do observador ou da observadora da gravura, o que faz do seu lado direito o lado esquerdo do observador. Em outras palavras, o caminho estreito do lado esquerdo, do ponto de visto do observador, conduz para o lado direito de Jesus. A gravura de 1619 mantém esta simbologia composicional, mesmo que o Cristo dos céus é agora o crucificado. Já a protestante pietista Reihlen parece ter uma perspectiva mais antropocêntrica, o que a leva a colocar o caminho estreito do lado direito, na perspectiva do observador ou da observadora. Além disso, Reihlen também não mantém a referência Épsilon de Pitágoras. 


\section{Elementos das xilografias de François Georgin e das gravuras de Hieronymus Wierix omissos na xilografia de Charlotte Reihlen}

Neste quarto tópico unimos os aspectos das xilografias dos três caminhos e dos dois caminhos de Wierix omitidos na xilografia de Charlotte Reihlen. Focamos em três, que pertencem ao imaginário da morte: as representações pictóricas do inferno, da morte e dos demônios.

Figura 12: Wierix, Hieronymus. O caminho estreito e largo, 1619. Detalhe: A boca do inferno.

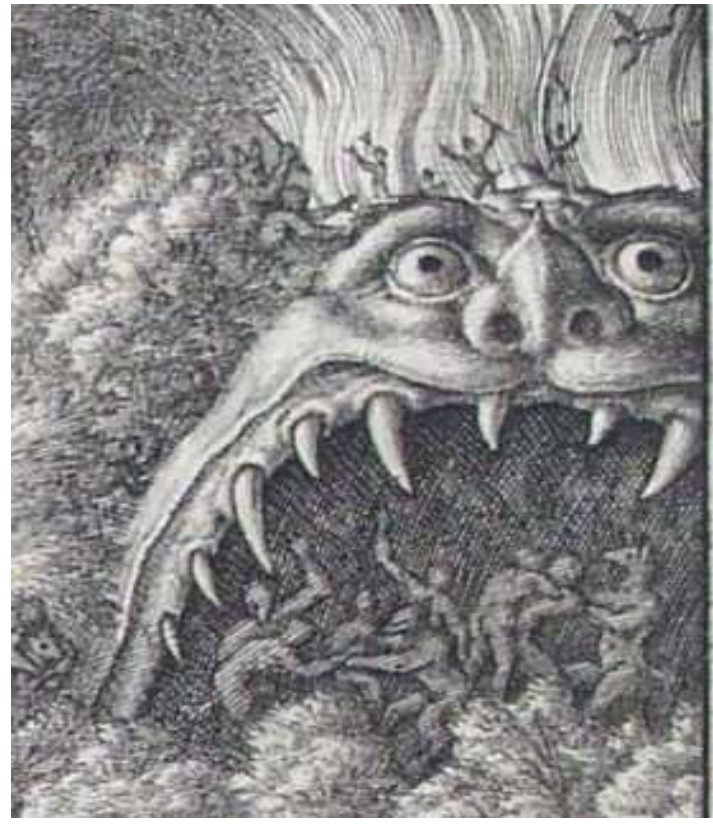

Fonte: Rijksmuseum, Holanda, 2016, [adaptada].
Figura 11: GEORGIN, François. $O$ novo Jerusalém, 1824, Detalhe: A boca do inferno.

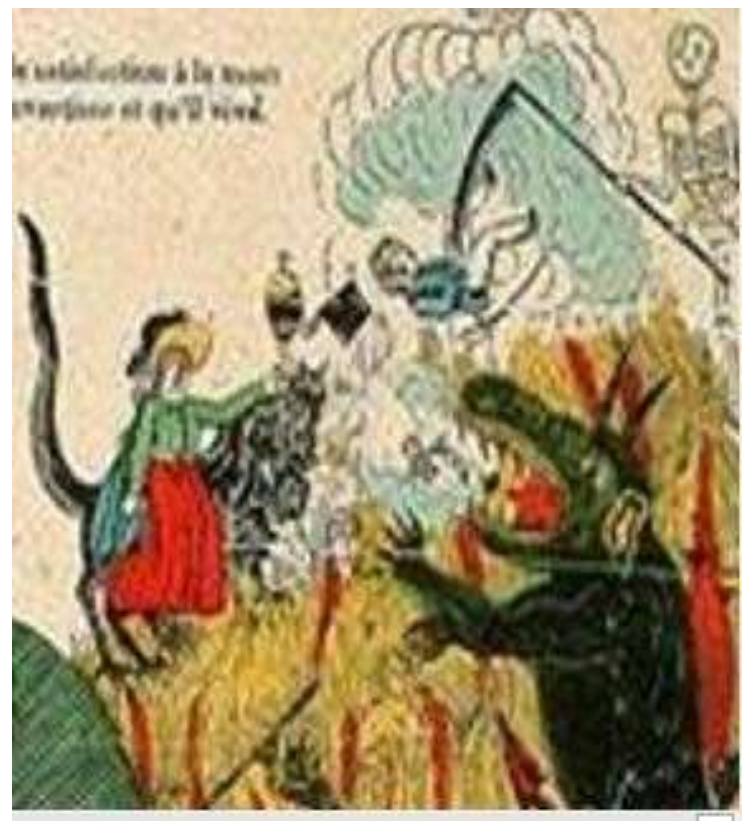

Fonte: Ministère de la Culture et de la Communication, France, 2016 
A primeira omissão se refere ao imaginário da boca do inferno, dominante ainda em Wierix (figura 11) e presente ainda em algumas xilografias de Georgin (figura 12). O motivo é muito conhecido na iconografia francesa e encontra-se, por exemplo, no tympanum do Juízo Final na Igreja de Sainte-Foy de Conques, França, construída entre 1050-1130 d.C. Sua origem, entretanto, não é nem bíblica nem greco-romana, mas anglo-saxã e viking. Em uso desde o ano 800 (SCHMIDT, 1995), o motivo foi criado na Inglaterra e, posteriormente, integrado ao imaginário religioso europeu como um todo (SCHAPIRO, 1987; 1984). Interessantemente, há versões dessa obra em que Georgin substitui a boca do inferno por demônios que torturam as pessoas no inferno (figura 16). Lembre-se que essa omissão já ocorreu na passagem de Kis para Ling e que Reihlen não retomou o elemento posteriormente.

O segundo elemento, não preservado em Reihlen, é a representação da morte por um esqueleto (figuras 13 e 14).

Figura 13: Wierix, Hieronymus, $O$ caminho estreito e largo, 1619. Detalhe: A morte impura leva o ser humano ao inferno.

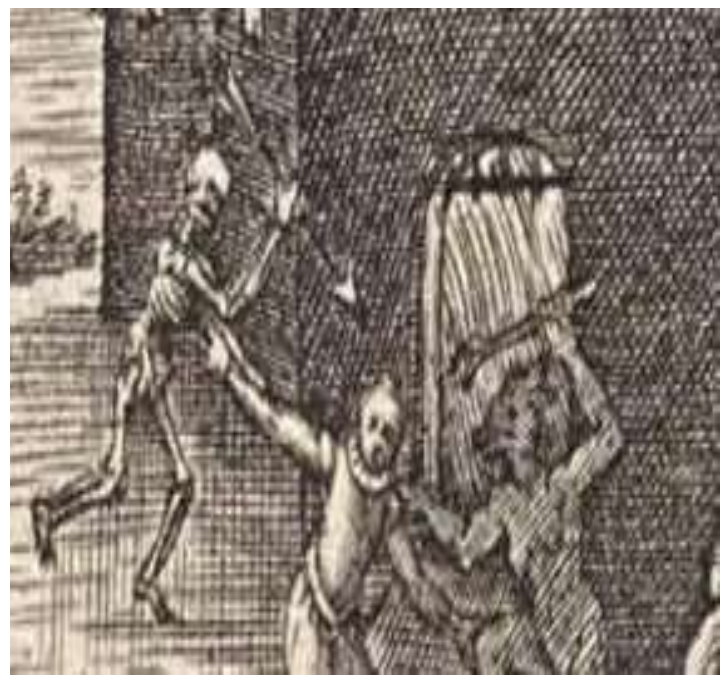

Fonte: Rijksmuseum, Holanda, 2016, [adaptada]
Figura 14: GEORGIN, François. Os três caminhos para a eternidade, 1850. Detalhe: A morte leva o ser humano ao inferno.

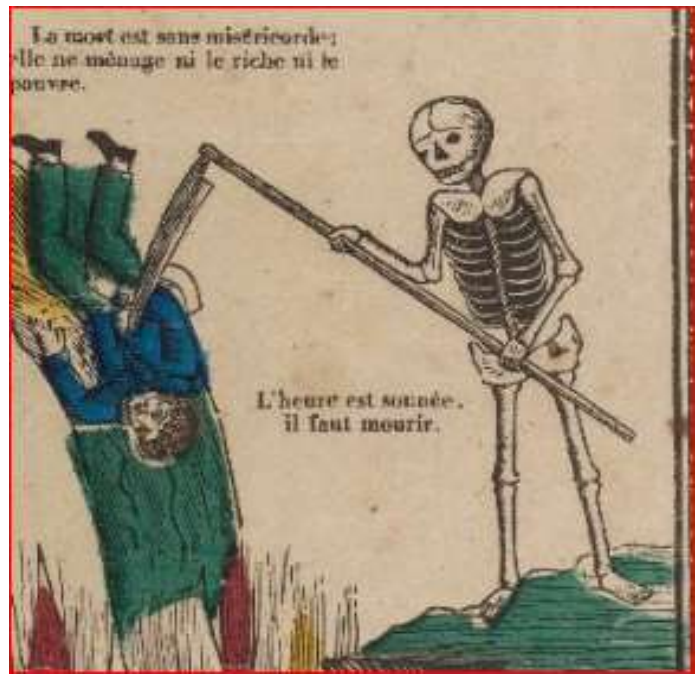

Fonte: Ministère de la Culture et de la Communication, France, 2016, [adaptada] 
Observe-se que, nas obras de Wierix (1600), Georgin (1825, 1839 e 1850) e Wentzel (1860), a morte ataca os vivos e os força para o inferno.

Vinculado a esses dois imaginários, há o terceiro, de um inferno lotado de demônios torturando os pecadores com flechas e lanças. Nas obras de Georgin, este imaginário substitui a boca do inferno a partir de sua segunda edição e predominam as edições de língua alemã.

Figura 15: Wierix, Hieronymus, De smalle en de brede Weg, 1600. Detalhe: Demônios maltratam as pessoas no inferno.

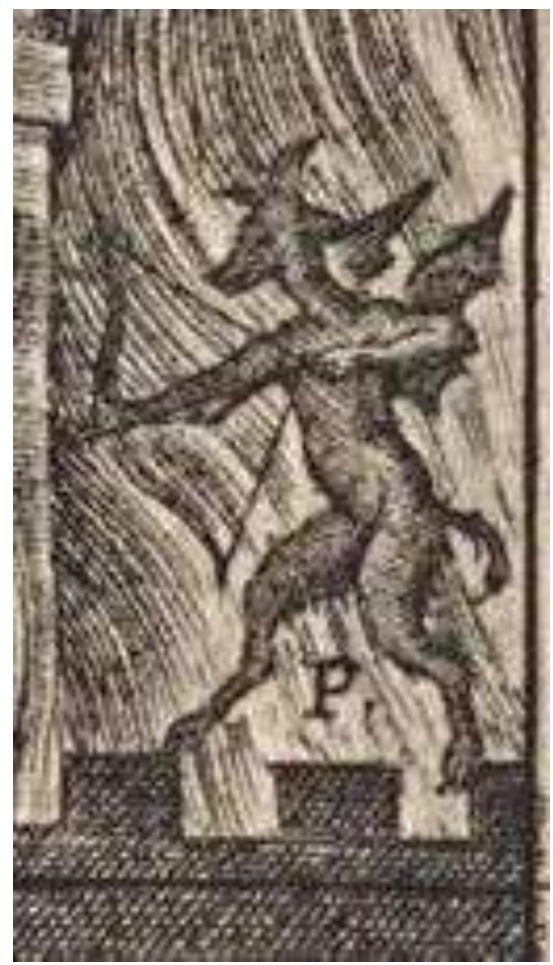

Fonte: Rijksmuseum, Holanda, 2016, [adaptada].
Figura 16: GEORGIN, François. $O$ caminho para o céu e o caminho para o inferno, 1839. Detalhe: Demônios maltratam as pessoas no inferno.

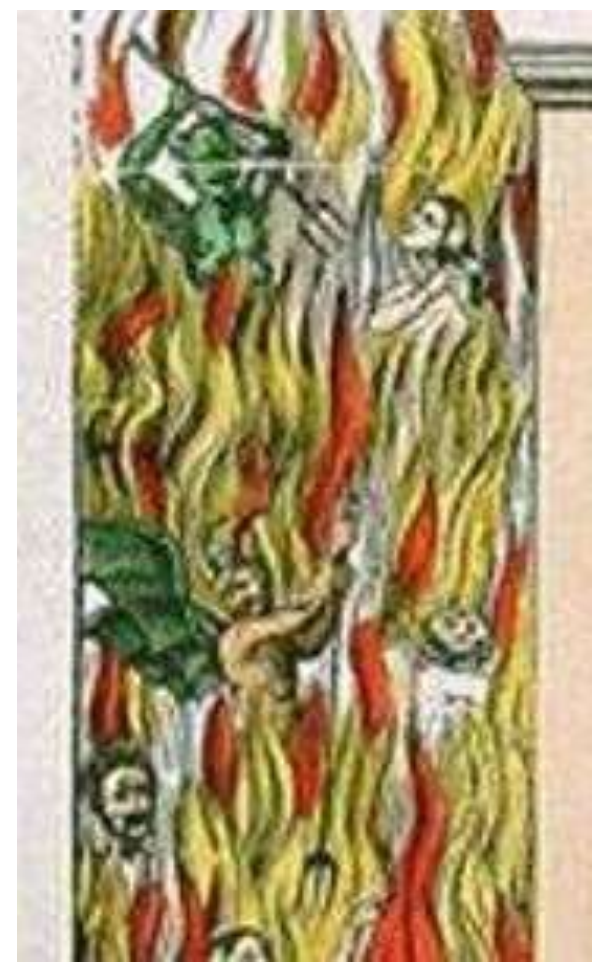

Fonte: Ministère de la Culture et de la Communication, France, 2016, [adaptada] 


\section{Figura 17: WENTZEL, A nova Jerusalém, 1860. Detalhe: Demônios maltratam as pessoas no inferno.}

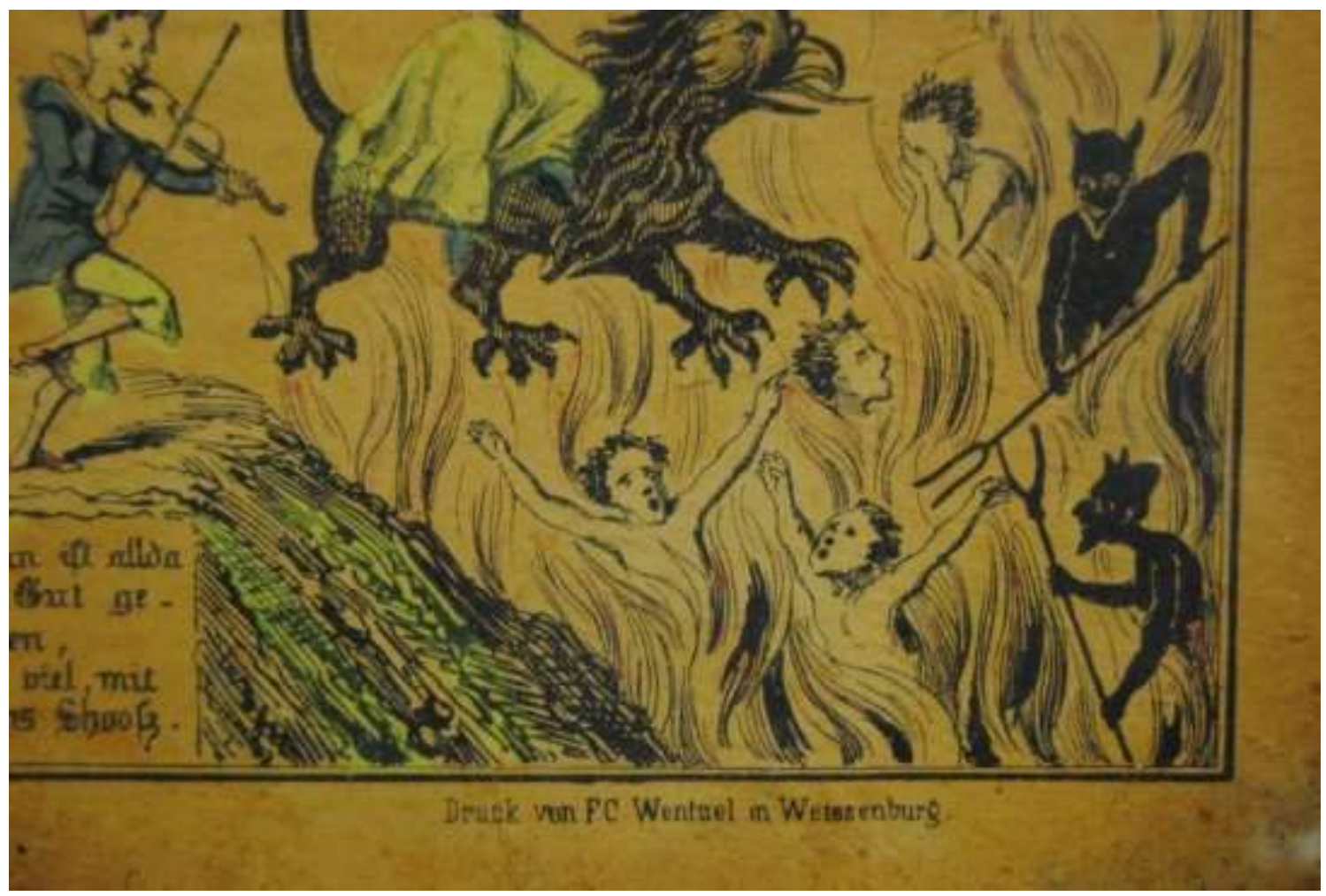

Fonte: Ebay, [original de 1860 - detalhe]

Entretanto, mais uma vez, há uma diferença entre as obras que seguem o motivo dos três caminhos e Wierix: em Wierix, demônios e anjos ou protegem e guiam ou atacam e forçam os/as peregrinos/as. O elemento da presença de demônios e anjos durante o trajeto já desaparece nas gravuras dos três caminhos: Céu e inferno são habitados por anjos e demônios, mas, aparentemente, não a terra. Em Reihlen, existem ainda anjos nas esferas celestiais.

Observe-se que a iconografia desses três elementos - boca do inferno, a morte como esqueleto e a presença de demônios - se manteve intacta nessas obras durante 225 anos (1600-1825). Depois, desapareceu sucessivamente (1837-1867). Já na obra de Charlotte Reihlen estes três elementos não são mais visualizados, ou seja, há na gravura de Reihlen uma tendência de "modernização" da linguagem visual e da substituição de certos motivos da linguagem visual medieval. 


\section{Considerações intermediárias}

Ao longo do tempo localizamos na América Latina, ao lado da obra de Reihlen, rastros “materiais” das obras de Wierix e Georgin. Encontramos cópias da gravura de Hieronymus Wierix, de 1600, na igreja da aldeia indígena de Andahuaylillas, perto de Cuzco (SUAREZ, 2013, p. 369-399; 2016a; 2016b, p. 187203; FERRERO, 2013, p. 40-55) e xilogravuras de François em igrejas católicas. Em outras palavras: a aceitação da obra de Reihlen em terras brasileiras pode ser explicada também pelo fato de não ser um ícone protestante "puro"; pelo contrário, deve se cogitar que alguns elementos da obra de Reihlen ajudaram na articulação em um meio católico, inclusive por ser visual.

Não sugerimos que esse conhecimento cultural era comum ou algo consciente na população protestante, recentemente "convertida". Isso não quer dizer que o fato não criou certa familiaridade, por trocar imagens, porém, sem modificar costumes: em vez de colocar o cartaz do sagrado coração de Jesus nos seus lares, penduraram o cartaz dos dois caminhos que, além de tudo, talvez poderia até aparecer estranhamente familiar, caso conhecessem as obras da reforma católica e os seus temas.

Entretanto, nosso artigo tinha em primeiro lugar o propósito de evidenciar a introdução de uma metodologia no estudo da religião, que permite ver as contribuições dos aspectos visuais dos discursos protestantes em contexto. A partir dessa perspectiva, aparecem aspectos transconfessionais que desafiam as interpretações que veem em Reihlen "o" discurso típico e uniforme do protestantismo. Diferentemente, protestantes se apropriaram parcialmente do imaginário religioso católico, inclusive de um imaginário declaradamente antiprotestante, para construir uma própria cultura visual evangélica. É evidente, que essa dinâmica não seguia as clássicas fronteiras e confrontações confessionais e que o nosso recorte cronológico, o ano de 1867, fica antes do Concílio Vaticano I, que teve início em 8 de dezembro de 1869 e terminou em 18 de dezembro de 1870. 
Que o tom entre as confissões depois desse concílio mudou, é evidente. Não obstante, a obra de Reihlen não se alterou e não pode ser simplesmente lida à base dos conflitos entre protestantes e os promotores do Vaticano I, o movimento ultramontano. Diferentemente, é uma expressão de um cristianismo que não é em primeiro lugar anticatólico, mas, conservador, e que destaca a fé pessoal.

\section{REFERÊNCIASS}

A CULTURAL CELEBRATION: Arts of the Pennsylvania Germans from a Berks County Private Collection June 12 - September 26, 2010 Curated by Louisa Bartlett. Disponível em: < http://www.readingpublicmuseum.org/pdf/Cultural_celebration_ booklet.pdf >. Acesso em: 20 fev. 2016.

BAILEY, Gauvin Alexander. Art on the Jesuit Missions in Asia and Latin America: 1542- 1773. Toronto: University of Toronto Press, 1999.

BERNET, Claus; SCHMIDT, Ingeborg. Das Zweiwegebild: Meisterwerke des Himmlischen Jerusalem, vol. 22, Editora: Books on Demand. 3a ed. 2016. [ebook/Kindle Editon];

BOHRER, Alex Fernandes. Os diálogos de Fênix: fontes iconográficas, mecenato e circularidade no Barroco mineiro. Dissertação (Mestrado em História). Universidade Federal de Minas Gerais. Belo Horizonte, 2007.

BUNYAN, John. Eines Christen Reise nach der seligen Ewigkeit. Harrisburg, Gustav G. Peters, 1832.

CAMPOS, Leonildo Silveira. O caminho estreito da 'salvação' e o caminho largo da 'perdição' : observações sobre um a iconografia protestante do século 19. In: CAMPOS, Leonildo Silveira; SILVA. Eliane Moura; RENDERS, Helmut. O estudo das religiões: entre a história, a cultura e a comunicação. Campinas: Editora da UNICAMP / Editora da Umesp, 2014a. p. 143-144.

CAMPOS, Leonildo Silveira. Os "dois caminhos: observações sobre uma gravura protestante. Horizonte, Belo Horizonte, v. 12, n. 34, p. 339-381, abr./jun. 2014b.

CORNELL. Georgin, François (gravador). Les 3 Chemins de l'Eternité. Metz: Dembour \& Gangel, 1840, Cornell University Library < https://digital.library.cornell.edu/catalog/ss:3293750 >. Acesso em: 20 fev. 2016.

CRANACH, O VELHO, Lucas. Lei e graça. Pintura a óleo, 1529. Disponível em: < https://de.wikipedia.org/wiki/Lucas_Cranach_der_\%C3\%84ltere\#/media/File:Cranach_ Gesetz_und_Gnade_Gotha.jpg >. Acesso em 20 ago. 2016. 
CRANACH, O VELHO, Lucas. Lei e graça, a justificação do pecador. Pintura, 1531. Disponível em: <

https://commons.wikimedia.org/wiki/File:Lucas_Cranach_d.\%C3\%84.__Allegorie_auf_Gesetz_und_Gnade_(Germanisches_Nationalmuseum).jpg >. Acesso em: 20 ago $201 \overline{6}$.

CRANACH, O VELHO, Lucas. Lei e graça. Pintura, 1536. Disponível em: < https://nordonart.files.wordpress.com/2014/01/lot-165.jpg >. Acesso em: 20 ago. 2016.

CRANACH, O VELHO, Lucas. Lei e evangelho. Pintura, 1551. Disponível em: < http://www.museum.evang.st/wp-content/uploads/2015/02/Gesetz-und-GnadeCranach.jpg >. Acesso em: 20 ago. 2016.

CZAJKOWSKI, Carmen. Pietismus in Wu“rttemberg im 19. Jahrhundert Technikfreunde oder Technikfeinde am Beispiel des Zwei-Wege-Bildes von Charlotte Reihlen. Darmstadt: Technische Universität. Dissertação de Mestrado, 2005.

DELCIDES, Marques. Da vida santificada: A moralidade do caminho estreito. Versão final da tese orientada pelo prof. Ronaldo Romulo Machado de Almeida. Unicamp, 2013.

FERRERO, Sebastián. "Les peintures murales à San Pedro d'Andahuaylillas: agriculture et spiritualité dans les Andes”. In: RACAR: revue d'art canadienne / Canadian Art Review, vol. 38, n. 2, p. 40-55 (2013).

GEHEUGENVANNEDERLAND. Wierix, Hiernonymus. De brede em de smalle Weg. [1619]. Disponível em: < http://www.geheugenvannederland.nl/?/nl/items/BVBo1:VOORLOPIG25PK >. Acesso em: 20 fev. 2016.

GOSSNER, Johannes Evangelista. Das Herz des Menschen: Ein Tempel Gottes oder eine Werkstätte des Satans In zehn Figuren sinnbildlich dargestellt. Harrisburg: publicado por Gustav G. Peters, PA, 1832.

HOPKIN, David M. Soldier and Peasant in French Popular Culture: 1766-1870. Woodbridge and Rochester, N.Y.: The Boydell Press and The Royal Historical Society, 2003.

KIRKHAM, Gawin. History and explanation of the picture "The Broad and the Narrow Ways” (with portrait). Londres, Morgan \& Scott, 1888.

KIS, Schmerzlicher Irrtum des üppigen Lebens jetziger Weltmenschen. Cannstatt, [Alemanha], [180o?]. [Tradução do título: Uma vida farta - engano doloroso das pessoas mundanas de hoje]. Disponível em: < https://www.wkgo.de/medien/Themen/16.\%20Inv.00.037.jpg >. Acesso em: 20 ago. 2016.

LANG, Friedrich G. Charlotte ..Reihlen (1805-1868) - Lebensweg und Zwei-WegeBild. Stuttgart: Verein fu" r wu" rttembergische Kirchengeschichte, 2014. 
LATOUR, Bruno. Jamais fomos modernos: Ensaio de antropologia simétrica. Trad. Carlos Irineu da Costa, Rio de Janeiro, Ed. 34, 1994.

LIBRARYCOMPANY. Peters, Gustav E. (ed.). New Jerusalem, [S.l.]: [s.e.], [não antes de 1830]. Disponível em: <

http://www.librarycompany.org/broadsides/images/large/Yoder9.2.jpg >. Acesso em: 20 fev. 2016.

LING, Johann Evangelist. Seelenspiegel oder der Wettlauf es alltäglichen Lebens. Ulm [Alemanha], 1840. [Tradução do título: Espelho da alma ou a corrido da vida cotidiana]. Disponível em: <

https://www.wkgo.de/medien/Themen/11.\%20Inv.92.255.jpg >. Acesso em: 20 ago. 2016.

MARTIN, Dennis. Images d'Epinal - images of Epinal. Quebec: Musee du Quebec, 1996.

MASSING, Jean Michel. "The Broad and Narrow Way from German Pietists to English Open-Air Preachers”. In: Print Quarterly, vol. 5, n. 3, p. 258-267 (set. 1988).

MAUQUOY-HENDRICK, Marie. Les estampes des Wierix. 4 vol. Bruxelas: 1978-1983. 691p. 2.335 ilustrações.

MESSIMERI, Eleftheria. Zwei-Wege-Bilder im altgriechischen Denken und ihre logisch-philosophische Relevanz. Würzburg: Königshausen \& Neumann, 2001.

METKEN, Sigrid. Französische Bilderbogen des 19. Jahrhunderts: Sammlung Sigrid Metken, Paris; Staatl. Kunsthalle Baden-Baden u. Ges. d. Freunde Junger Kunst e. V., 14. April-28. Mai. Baden-Baden, 1972.

MINISTÈRE DE LA CULTURE ET DE LA COMMUNICATION, FRANCE. Georgin, François (gravador). La nouvelle Jerusalem. Epinal: Pellerin (ed.), 1824. Disponível em: < http://www.culture.gouv.fr/Wave/image/joconde/0661/mo53702_000961_p.jpg >. Acesso em: 20 fev. 2016.

MINISTÈRE DE LA CULTURE ET DE LA COMMUNICATION, FRANCE.Georgin, François (gravador). Les 3 Chemins de l'Eternité. Metz: Dembour \& Gangel, 1840. Disponível em: < http://www.culture.gouv.fr/Wave/image/joconde/o661/mo53702_000962_p.jpg >. Acesso em: 20 fev. 2016. Uma versão com uma colorização diferenciada e excelente resolução encontra-se na Cornell University Library < https://digital.library.cornell.edu/catalog/ss:3293750 >. Acesso em: 20 fev. 2016.

MINISTÈRE DE LA CULTURE ET DE LA COMMUNICATION, FRANCE. Georgin, François (gravador). Le chemin du Ciel et le chemin de l'Eternité. Epinal: Pellerin, (ed.), 1837. Disponível em: < http://www.culture.gouv.fr/Wave/image/joconde/o661/ mo53702_000964_p.jpg >. Acesso em: 20 fev. 2016. 
MONTEIRO, Douglas Teixeira. "Sobre os Dois Caminhos". In: Cadernos do Instituto Superior de Estudos da Religião (ISER). Rio de Janeiro, Tempo e Presença Editora LTDA, n. 5, nov. 1975. p. 21-29.

MORGAN, David. "Image of the Protestant Bible in America". In: CHANCEY, Marc E.; MEYERS, Carol; MEYERS, Eric M. (eds.). The Bible in the public square: its enduring influence on American life. Atlanta, Georgia: SBL Press. 2014 p. 93-119.

MORGAN, David. "Protestant Visual Culture in urban America during the Progressive Era”. In: GIGGIE, John M.; WINSTON, Diana (eds.). Faith in the market. Religion and the rice of urban commercial culture. New Brunswick, New Jersey, London: Rutgers University Press, 2002. p. 37-56.

MORGAN, David. Protestants \& pictures: Religion, Visual Culture, and the Age of American Mass Production. New York e Oxford: Oxford University Press, 1999.

MUSEUMSCOLLECTION. Peters Cf. Disponível em: < http://mhep.org/wpcontent/uploads/2013/o9/museumcollection G.jpg >. Acesso em: 6 fev. 2016.

OLSCHKI, Leo S. La Bibliofilia: Rivista di storia del libro e di bibliografia.vol. 36, Firenze: L.S. Olschki, 1935.

PANOFSKY, Ernst. "Iconografia e Iconologia: Uma introdução ao estudo da arte da Renascença”. In: Significado nas Artes Visuais. Tradução: Maria Clara F. Kneese e J. Guinsburg. São Paulo: Perspectiva, $2^{\mathrm{a}}$ ed., 1986, p. 47-65;

PANOFSKY, Ernst. Hercules am Scheidewege. Und andere antike Bildstoffe in der neueren Kunst. Berlin: Mann, 1937.

PIESKE, Christa. “The European origins of for Pennsylvania German Broadsheet themes: Adam and Eve; The New Jerusalem; The broad and narrow way; the unjust judgement the stages of life". In: Der Reggeboge: Journal of the Pennsylvania German Society, Breinigsville, Pennsylvania, EUA, vol. 23, p. 13-22 (1989).

RENDERS, Helmut. “A gravura O caminho estreito e o caminho largo de Hieronymus Wierix de 1600: uma análise panofskiana de uma obra da reforma católica com ecos latinoamericanos”. In: Estudos da Religião, São Bernardo do Campo [texto submetido];

RENDERS, Helmut. “A religio pectorum `evangélica’ e a religião ‘cordial’ brasileira: articulação de cidadania ou sinal de adaptação à matriz cultural dominante?". In: CAMPOS, Leonildo Silveira; SILVA. Eliane Moura; RENDERS, Helmut. O estudo das religiões: entre a história, a cultura e a comunicação. SBC / Campinas: Editora da UNICAMP / Editora da Umesp, 2014. p. 183-224

RENDERS, Helmut. “A tradução do livro católico O coração do ser humano, de J. E. Gossner (1812), pelo presbiteriano A. Jensen (1914): promoção de um imaginário católico ou sua releitura protestante?”. In: Estudos de Religião, São Bernardo do Campo, SP, vol. 26, n. 43, p. 77-105 (jul./dez. 2012). 
RENDERS, Helmut. “As origens do livro emblemático O coração do ser humano (1812) de Johannes Evangelista Gossner: continuidade e releituras da religio cordis nos séculos 16 a 19”. In: Protestantismo em Revista, São Leopoldo, RS, vol. 29, p. 65-78 (set./dez. 2012).

RENDERS, Helmut. "De smalle en de brede Weg de Hieronymus Wierix do ano 1619: uma leitura panofskiana de uma gravura da reforma católica”. Visualidades, Goiás. Texto submetido.

RENDERS, Helmut. “Imaginário religioso católico - protestante - pentecostal neopentecostal? implicações da origem e múltiplas reedições do livrinho do coração e em solo brasileiro". In: Ciências da Religião, História e Sociedade, vol. 7, n. 2, p. 116-153 (2009)

SAINT-MARTIN, Isabelle. "La sanctification du dimanche: un combat par l'image", In: Histoire, économie \& société, ano 28, n. 3, p. 85-98 (2009)

SANTIAGO, Camila Fernanda Guimarães. Usos e impactos de impressos europeus na configuração do universo pictórico mineiro (1777-1830). Tese (Doutorado em História). Universidade Federal de Minas Gerais. Belo Horizonte, 2009.

SANTOS, Lyndon de Araújo. "Dois Caminhos: um paradigma da crença protestante no Brasil”. In: MANOEL, Ivan Aparecido \& FREITAS, Nainora Maria Barbosa de (Orgs.). História das Religiões: desafios, problemas e avanços teóricos, metodológicos e historiográficos. São Paulo: Paulinas, 2006. pp. 217-244 (Coleção estudos da ABHR)

SANTOS, Lyndon de Araújo. As outras faces do sagrado: protestantismo e cultura na Primeira República Brasileira. São Luís: Editora da Universidade Federal de Maranhão, 2006.

SANTOS, Lyndon de Araújo. Protestantes na República Velha. ASSIS, SP: Editora da Unesp, 2004.

SCHARFE, Martin. "Zwei-Wege-Bilder. Volkskundliche Aspekte evangelischer Bilderfrömmigkeit“. In: Blätter für württembergische Kirchengeschichte, Stuttgart, vol. 90, pp. 123-144 (1990).

SCHAPIRO, Meyer. Estudios sobre el arte de la Antiguedad Tardia, el Cristianismo Primitivo y la Edad Media. Madrid: Aliana Editorial, 1987.

SCHAPIRO, Meyer. Estudios sobre el Romanica. Madrid: Aliana Editorial, 1984.

SCHARFE, Martin. Die Religion des Volkes: Kleine Kultur- und Sozialgeschichte des Pietismus. Gütersloh: Gerd Mohn Verlag, 1980, p. 84-87.

SCHARFE, Martin. Evangelische Andachtsbilder. Studien zu Intention und Funktion des Bildes ind er Frömmigkeitsgeschichte vornehmlich des schwäbischen Raumes. Stuttgart: Müller u. Gräff, 1968. 
SCHARFE, Martin. Volksfrömmigkeit: Bildzeugnisse aus Vergangenheit und Gegenwart. Stuttgart: Spectrum-Verlag, 1967.

SCHARFE, Martin. "Zwei-Wege-Bilder. Volkskundliche Aspekte evangelischer Bilderfrömmigkeit“. In: Blätter für württembergische Kirchengeschichte, vol. 90, pp. 123-144 (1990).

SCHMIDT, Gary D. The iconography of the Mouth of hell: eighth-century Britain to the fifteenth century. Selinsgrove, PA / Cranbury, NJ: Susquehanna University Press / Associated University Presses, 1995.

SHANTZ, Douglas. A Companion to German Pietism, 166o-18oo. Leiden: Brill, 2005. p. 158.

STRATEN, Roelof van. The Wierix family. Leiden: Foleor, 2010.

SUAREZ, Ananda Cohen. "Painting Andean Liminalities at the Church of Andahuaylillas, Cuzco, Peru”, In: Colonial Latin American Review, vol. 22, n. 3, p. 369-399 (2013).

SUAREZ, Ananda Cohen. Heaven, hell, and everything between: murals of the colonial Andes. Austin: University of Texas Press, 2016.

SUAREZ, Ananda Cohen. Making race visible in the colonial Andes. In: PATTON, Pamela A. Envisioning Others: Race, Color, and the Visual in Iberia and Latin America. Leiden, 2016. p 187-203.

WHAREY, James Blanton (ed.). The Pilgrim's Progress from this world to that which is to Come. 2 ed. Oxford: Clarendon Press, 1960.

VON HAUF, ADELHEID M. Frauen gestalten Diakonie (vol. 2): Vom 18. bis zum 20. Jahrhundert. Stuttgart: W. Kohlhammer Verlag, 2006. 